\title{
Effect on flower thinning by using nano-processing technology chemicals in plum (Prunus salicina Linnaeus)
}

\author{
Seung Hyun Lee ${ }^{1}$, Seung Min Lee ${ }^{2}$, Soojeong So ${ }^{2}$, Yun-Sik Choi ${ }^{3}$, Yoon Hee Jang ${ }^{4}$, Kyung-Min \\ $\mathrm{Kim}^{4 *}$ and II Kyung Chung ${ }^{1 *}$ \\ ${ }^{1}$ Department of Biotechnology, Daegu Catholic University, Gyeongsan-si, Gyeongsanbuk-do, 38430, Korea. \\ ${ }^{2}$ Institute in Natural Science Techonolgy, Gyeongsan-si, Gyeongsanbuk-do, 38430, Korea. \\ ${ }^{3}$ Department of Pharmacology, College of Pharmacy, Kyungsung University, Nam-Gu, Busan-Si, 48434, Korea. \\ ${ }^{4}$ School of Applied Biosciences, College of Agriculture and Life Sciences, Kyungpook National University, Daegu, 41566, \\ Korea.
}

Accepted 26 July, 2018

\begin{abstract}
In this study, we investigated the effect of flower thinning chemicals using wet nano-technology on the rate of flower thinning and yield of high-quality fruit. We confirming the flower thinning rate, crop load and fruit set rate, the rate of flower thinning of 500 times and 250 times diluted solution was 5.7 times and 3.8 times higher than that of the control, respectively and the fruit set rate was 2.2 times, 3.4 times. To confirm the fruit quality characteristics of the plums of different cultivars, we sprayed the flower thinning chemicals prepared through the nano-processing on the Royaldaeseok, Formosa and Hongosen cultivars and compared the crop load, fruit weight and fruit size. Overall, the fruit weight and fruit size were higher in the plums of all cultivars sprayed with flower thinning chemicals than the control group. We were concluded that the use of flower thinning chemicals by wet nano-process technology could inhibit the number of fruit set and produce high-quality fruit in fruit trees other than plums. In addition, it is expected to be applicable to various fields because it can be used in natural products and bio industries as well as plant nutrients.
\end{abstract}

Keywords: Flower thinning chemicals, nano technology, plums, scanning electron microscopy.

*Corresponding author. E-mail: chungik@cu.ac.kr, kkm@knu.ac.kr.

\section{INTRODUCTION}

Plum is an old fruit that has been cultivated since the Silla Dynasty. It is a fruit of the subgenus Prunus of the genus Prunus and can be divided into Japanese plums (Prunus salicina), European plums (Prunus domestica) and American plums (Prunus americana) from North America depending on their origin. All of the plums cultivated in Korea are Japanese plums, which are highly watery and have a high sweetness, suitable for reproduction, strong against cold, and highly adaptable to the soil, so that they can be cultivated nationwide. The cultivars of Japanese plums are Daeseokjosaeng, Beauty, Formosa, Santa Rosa, Saddam, and Calcish.

The plum 'Royaldaeseok' is a variant of
Daeseokjosaeng and large size cultivar over $130 \mathrm{~g}$. It is easy to cultivate so that it can be harvested with only 1 2 times of sterilization and its maturation period is from the late in June to the early in July. The sugar content is 12 to 14 brix, the skin is reddish, and the flesh is yellowish white. When full ripe, it is dark red with good sweetness and good taste, and it has hard flesh and low acidity. In addition, the tree vigor is strong, and the decrease of sugar content is low when rainfall, and selfincompatibility so that requires pollinizer such as Formosa and Santa Rosa. 'Formosa' is one of the most cultivated cultivars in Korea and its weight is $130 \mathrm{~g}$. The maturation period is mid-July, the sugar content is 13 brix, 
the color is greenish red, and the flesh color is yellowish white. Usually, 5 to 40 flowers bloom in a flower, about 30 days after full bloom, one to three fruits are left per flower cluster, and at least one fruit per flower cluster remains when physiological fallout occurs normally (Yun et al., 2013). In addition, in the year when precipitation is high, balance of tastiness and freshness is harmed, and tasteless fruits are produced. The plum 'Hongrosen' cultivars are popular as a summer fruit as a substitute for Formosa. The maturation period is from early July to midJuly and its weight is $170 \mathrm{~g}$ and sugar content is $17 \mathrm{brix}$. It has high sugar content and good flavor, and the color is crimson so that it have excellent marketability. It is also easy to cultivate and self-fertilize. The composition of plums is $85 \%$ moisture, $12.6 \%$ carbohydrate, $1.1 \%$ fiber, very small amount of minerals and some water soluble vitamins. The content of calcium in the minerals is 2 to 4 times higher. In addition, plums contain a relatively large amount of useful components such as malic acid, citric acid, and other organic acids, fructose, free amino acids, and carotenoids (Chung, 1999). In this study, we will investigated the effect of flower thinning chemicals using wet nano-technology on the rate of flower thinning and yield of high-quality fruit.

\section{MATERIALS AND METHODS}

\section{Experimental material and design}

The plum cultivars (Prunus salicina) were selected from, Gunwi Agriculture Technology Center, Hyou-ro, Hyoryeong-myeon, Gunwigun, Gyeongsangbuk-do, Gyongsangbuk-do Agricultural Research, Chilgokjungang-daero, Buk-gu, Daegu and Cheongtong-myeon, Yeongcheon-si and identified directly. The flower thinning chemicals of plum manufactured in this study was a waterdispersible formulation of insoluble calcium and magnesium by Nanotechnology. It is a grinded flower thinning chemicals containing insoluble calcium and magnesium for more than 5 hours using a wet grinder (Rotate Mill; Amstech. Co. Ltd., South Korea), and it is expected that the absorption rate is increased due to reduction of particle size due to ultrafine grinding (Zhang et al., 2005). The nanoparticle size was confirmed using a particle size analyzer (Nano ZS, Malvern, UK)

\section{Nanotechnology process}

The nanotechnology used in this study was a wet nano grinding technology whose importance is increasing with the development of biotechnology and medicine. It is a technique suitable for grinding biological raw materials such as cells and is processed by using Ring mill equipment. The principle of the Ring mill is that the raw material flows into the interior of the dispersed vessel, collides with the beads filled in the interior of the dispersed vessel and is then crushed and passed through the screen outside the vessel. Through the repetition of this process, the particles become smaller and nano-sized. The flower thinning chemicals agent used in this study was prepared by mixing $10 \%$ of calcium acetate, $15 \%$ of calcium carbonate, $2 \%$ of magnesium carbonate, $0.5 \%$ of zinc sulfate, $0.14 \%$ of boric acid and $0.5 \%$ of tween- 80 in the total weight of the preparation. The solvent was water. The particle size of the flower thinning was gradually decreased according to the time of the nano-forming process, and when grinded for 4 hours or more, a formulation having a particle size of about $700 \mathrm{~nm}$ or less can be produced.

\section{Effect of spraying plum flower thinning chemicals}

In order to observe the flower thinning effect of plum using the flower thinning chemicals prepared by the nano-process, Chilgokjungang-daero, Buk-gu, Daegu City was selected as the target tree. And plum trees were sprayed with 250 times and 500 times diluted flower thinning chemicals at 3 trees, respectively. We compared the size, fruit weight and crop load by setting plums that did not spray flower thinning chemicals as control. In order to observe the fruit quality characteristics of the plums of the cultivars. The Gunwi Agriculture Technology Center, Hyou-ro, Hyoryeongmyeon, Gunwi-gun, Gyeongsangbuk-do were selected as the target trees and Royaldaesuk, Formosa and Hongosen cultivars were sprayed with 250 times and 500 times diluted flower chemicals using flower thinning chemicals using nano-processing technology. In treated tress Fruit size, weight, and number were compared by controls. The fruit number of the irradiated samples was measured three times per cultivars, and the size and the weight of the fruit were expressed as the average value of 10 fruits.

\section{Analysis of $\mathrm{Ca}$ and $\mathrm{Mg}$ contents of plum tree leaves}

In order to observe the plum tree composition in the area sprayed with the flower thinning chemicals, Daeseokjosaeng plum farm located in Aeryeon-gil, Cheongtong-myeon, Yeongcheon-si was selected as the target tree, and the flower thinning chemicals was sprayed twice during 2 months. The leaves were collected from control group, 1 week, 2 weeks, 4 weeks, 8 weeks after the flower thinning chemicals were sprayed to observe the movement of $\mathrm{Ca}$ and $\mathrm{Mg}$ in the leaves of the plums. The plum leaves were separated into leaf lamina and petiole, and were fixed on a sample holder and plated at $35 \mathrm{~mA} / \mathrm{mbar}$ for about $55 \mathrm{~s}$ in a Cressington 108 auto SEM sputter coater machine (Cressington Sientific Instruments Inc, Cranberry Twp, PA). This experiment was carried out by confirming the effect of the flower thinning chemicals using nano-processing technology through the Calcium and magnesium contents of the control group analyzed by SEM (Scanning Electron Microscopy) and EDS (Energy Dispersive Spectrometry) using a field emission scanning electron microscope (JSM-6335F, JEOL, Japan) (Yoo et al., 2016; Park et al., 2013; Kim et al., 1998). An Electron Microscope is an apparatus that creates an enlarged image of an object using an electron beam instead of a used in a light microscope, and an electronic lens instead of a glass lens. Because the electron beam is used instead of the visible rays, the inside of the microscope must be in vacuum. The electron is difficult to control as desired, such as energy is lost or refracted when it collides with the air. The electron microscope is magnified by the intensity of the current passing through the coils of the intermediate lens and the projection lens, and the focus of the image is controlled by the current flowing through the coil of the objective lens. Elastic scattering and inelastic scattering occur as the electron beam collides against the surface of the sample. And inelastic scattering causes secondary electrons, reflected electrons, characteristic and continuous X-rays, and phonon due to lattice vibration.

EDS is an optional feature attached to the SEM, and it is a component analysis device. The principle of component analysis is to use X-ray. When the electron beam is scanned in the specimen, it is excited by the energy in the atom. The electrons generated at this time are stabilized and emit a specific X-ray. Since the intrinsic energy that emits a specific X-ray differs for each substance, this value is used to analyze the constituents of the substance. After the 
EDS were taken, the growth rate of calcium and magnesium in the plum leaves was calculated according to the following formula:

Concentration of heavy metals in soil $(\mathrm{mg} / \mathrm{kg})=\left(\mathrm{C}_{1}-\mathrm{C}_{0}\right) / \mathrm{W}_{\mathrm{d}} \mathrm{XfXV}$

$\mathrm{C}_{1}$ : Heavy metal concentration of the analytical sample obtained from the calibration curve $(\mathrm{mg} / \mathrm{L})$

$\mathrm{C}_{0}$ : Heavy metal concentration of reagent base sample obtained from the calibration curve $(\mathrm{mg} / \mathrm{L})$

$\mathrm{W}_{\mathrm{d}}$ : Dry weight of the soil sample $(\mathrm{kg})$

$\mathrm{f}$ : Dilution factor of the test solution (arsenic is 25 if out of the range of the calibration curve)

$\mathrm{V}$ : The volume of the test solution (here $0.1 \mathrm{~L}$ ).

\section{RESULTS AND DISCUSSION}

The results of the flower thinning rate, crop load and fruit set rate of the plums are shown in Table 1. In the control group, the rate of flower thinning was $4.5 \%$, but $25.7 \%$ at dilution of 500 times and $17.2 \%$ at dilution of 250 times, respectively, which were 5.7 times and 3.8 times higher than those of the control group respectively. There was no statistical difference according to dilution rate. The fruit set rate was $12.6 \%$ in control group, $5.7 \%$ in 500 times diluted solution treatment and $3.7 \%$ in 250 times diluted solution treatment, which were 2.2 times and 3.4 times higher respectively. The crop load by treatment with flower thinning chemicals was 108 in control group, 56 in 500 times diluted solution and 26 in 250 times diluted solution treatment, which were twice and four times higher, respectively. In addition, after 3 days from the spraying of flower thinning chemicals, the appearance of flowering and fruit set seemed to have no problem in flowering when using the flower thinning chemicals (Figure 1).

The results of the crop load according to dilution of the plum flower thinning chemicals were as follows (Table 2). The fruit number of the irradiated samples was measured three times per cultivars. The fruit number in the control group of Royaldaeseok was 108, 105 in 500 times diluted solution treatment and 87 in 250 times diluted solution treatment. The effect of dilution of 250 times compared to the control group was $19 \%$. The fruit number in the control group of Formosa was 105, 99 in 500 times diluted solution treatment and 85 in 250 times diluted solution treatment. And 5\% and 19\% compared to the control group, respectively. The fruit number in the control group of Hongrosen was 102, 89 in 500 times diluted solution treatment and 53 in 250 times diluted solution treatment which was $13 \%$ and $48 \%$ higher respectively.

The results of the fruit weight according to number of the application of flower thinning chemicals were as follows (Table 3 ). The average value of 10 fruits was measured. The control of Royaldaeseok was $77 \mathrm{~g}$, the weight was $110 \mathrm{~g}$ when applied once, and the weight was $83 \mathrm{~g}$ when applied twice, which showed 43 and $8 \%$ as compared with the control, respectively. The control of Formosa was $77 \mathrm{~g}$, the weight was $123 \mathrm{~g}$ when applied once, and the weight was $117 \mathrm{~g}$ when applied twice, which showed 60 and $52 \%$ as compared with the control, respectively. The control of Hongrosen was $77 \mathrm{~g}$, the weight was $88 \mathrm{~g}$ when applied once, and the weight was $98 \mathrm{~g}$ when applied twice, which showed 14 and $27 \%$ as compared with the control, respectively.

The results of the fruit size according to number of the application of flower thinning chemicals were as follows (Table 4). The average values of the measurements of the horizontal and vertical sizes of the 10 fruits are shown. The control size of Royaldaeseok was $5.3 \mathrm{~cm}$, the size of one spray was $6.1 \mathrm{~cm}$, and the size of spray was $5.5 \mathrm{~cm}$, which was 15 and $4 \%$ as compared with the control, respectively. The control size of Formosa was $5.1 \mathrm{~cm}$, the size of one spray was $6.1 \mathrm{~cm}$, and the size of spray was $6.2 \mathrm{~cm}$, which was 20 and $22 \%$ as compared with the control, respectively. The control size of Hongrosen was $5 \mathrm{~cm}$, the size of one spray was $5.3 \mathrm{~cm}$, and the size of spray was $5.4 \mathrm{~cm}$, which was 6 and $8 \%$ as compared with the control, respectively.

This seems to have been influenced by an increase in cell division at the early stage of growth due to treatment with flower thinning chemicals and an increase in fruit size due to promotion of fruit overgrowth (Cho and Yoon, 2006; Garcia-Pallas et al., 2001). Therefore, we have found that the use of flower thinning chemicals prepared through the nano process could inhibit the growth of crop load and obtain high quality fruits.

The $\mathrm{Ca}$ and $\mathrm{Mg}$ content were analyzed through SEM, EDS scans, dividing the plum leaves into lamina, petiole, and side of lamina. As a result of measurement of $\mathrm{Ca}$ and $\mathrm{Mg}$ content of petiole (Figure 2), 149\% in the control group ( 0 week), $365 \%$ in the 1 week, $1,555 \%$ in the 2 weeks, $74 \%$ in the 4 week and $286 \%$ increased compared with non-spraying group. In particular, $\mathrm{Mg}$ and Ca content was the highest in the 2 weeks after spraying. And 1 week after the second spraying, it was still high in $\mathrm{Ma}$ and $\mathrm{Ca}$ content. As time passed, spray group had more $\mathrm{Mg}$ and $\mathrm{Ca}$ than non-spraying group. The results suggest that the $\mathrm{Mg}$ and $\mathrm{Ca}$ content of nano flower thinning chemicals have moved to petiole.

The $\mathrm{Ca}$ and $\mathrm{Mg}$ content were analyzed through SEM, EDS scans, dividing the plum's leaves into lamina, petiole, side of lamina. The result of measuring the content by separating the lamina into the front and back is shown in Figure 3. The $\mathrm{Mg}$ and $\mathrm{Ca}$ content of lamina measurement showed 0 weeks $87 \%, 47 \%, 1$ week $28 \%, 775 \%, 2$ weeks $2,847 \%, 442 \%$, 4 weeks $120 \%, 73 \%$ and in the 8 weeks, the front and back sides increased by $160 \%$ and $132 \%$, respectively. In particular, $\mathrm{Mg}$ and $\mathrm{Ca}$ content were the highest in the 2 week after spraying. And 1 week after the second spraying, it was still high in Ma and Ca content. As time passed, spraying group had more $\mathrm{Mg}$ and $\mathrm{Ca}$ than non-spraying group. The results suggest that the $\mathrm{Mg}$ and $\mathrm{Ca}$ content of nano flower thinning chemicals have moved to the front and back of the lamina.

The $\mathrm{Ca}$ and $\mathrm{Mg}$ content were analyzed through SEM, EDS scans, dividing the plum leaves into lamina, petiole, 
Table 1. Crop Load and fruit set rate of the plums by spraying flower thinning chemicals.

\begin{tabular}{lccc}
\hline Treatment & Flower thinning rate (\%) & Crop load (piece) & Fruit set rate (\%) \\
\hline Control & $4.5 \pm 0.1^{\mathrm{b}}$ & $108 \pm 11.2^{\mathrm{a}}$ & $12.6 \pm 0.2^{\mathrm{a}}$ \\
500 times dilution & $25.7 \pm 0.2^{\mathrm{a}}$ & $56 \pm 2.2^{\mathrm{a}}$ & $5.7 \pm 0.1^{\mathrm{b}}$ \\
250 times dilution & $17.2 \pm 0.1^{\mathrm{ab}}$ & $26 \pm 3.1^{\mathrm{a}}$ & $3.7 \pm 0.1^{\mathrm{b}}$ \\
\hline
\end{tabular}

Mean values \pm standard error represent the analyzed data pooled from three independent consecutively conducted experiments. Values in a column accompanied with different small letters are significantly different at $\mathrm{P}<0.05$ as indicated by DMRT.

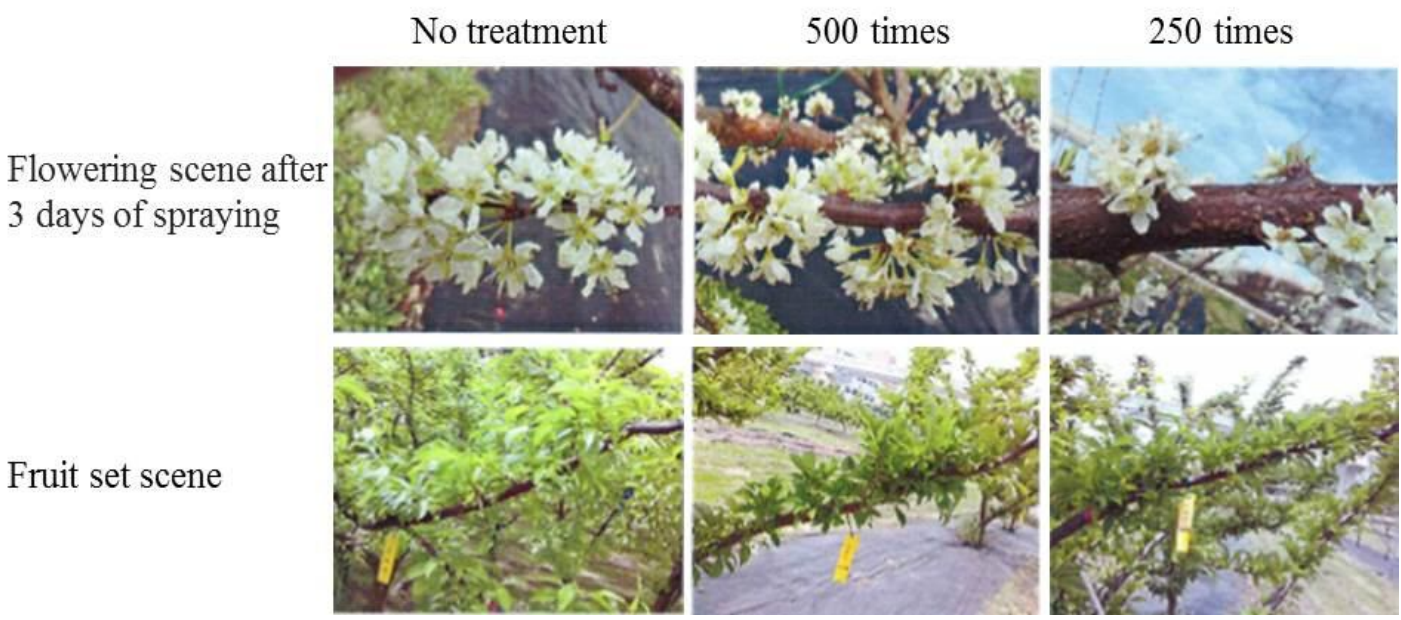

Figure 1. Flowering scene after spraying the flower thinning chemicals. After 3 days from the spraying of flower thinning chemicals, the appearance of flowering and fruit set seemed to have no problem in flowering when using the flower thinning chemicals.

Table 2. Crop load according to dilution of the flower thinning chemicals.

\begin{tabular}{lccc}
\hline Treatment & Royaldaeseok & Formosa & Hongrosen \\
\hline Control & $108 \pm 3.9^{\mathrm{a}}$ & $105 \pm 1.1^{\mathrm{a}}$ & $102 \pm 7.2^{\mathrm{a}}$ \\
500 times dilution & $115 \pm 10.2^{\mathrm{a}}$ & $99 \pm 1.1^{\mathrm{ab}}$ & $89 \pm 3.3^{\mathrm{a}}$ \\
250 times dilution & $87 \pm 5.6^{\mathrm{b}}$ & $85 \pm 2.1^{\mathrm{b}}$ & $53 \pm 4.6^{\mathrm{b}}$ \\
\hline
\end{tabular}

Mean values \pm standard error represent the analyzed data pooled from three independent consecutively conducted experiments. Values in a column accompanied with different small letters are significantly different at $\mathrm{P}<0.05$ as indicated by DMRT.

Table 3. Fruit weight according to the number of application of flower thinning chemicals $(\mathrm{g})$.

\begin{tabular}{lccc}
\hline Treatment & Royaldaeseok & Formosa & Hongrosen \\
\hline Control & $77 \pm 3.3 \mathrm{~b}$ & $77 \pm 7.7 \mathrm{~b}$ & $77 \pm 4.2 \mathrm{~b}$ \\
Applied once & $110 \pm 2.9 \mathrm{a}$ & $123 \pm 8.1 \mathrm{a}$ & $88 \pm 6.8 \mathrm{ab}$ \\
Applied twice & $83 \pm 9.3 \mathrm{a}$ & $117 \pm 8.1 \mathrm{a}$ & $98 \pm 1.1 \mathrm{a}$ \\
\hline
\end{tabular}

Mean values \pm standard error represent the analyzed data pooled from three independent consecutively conducted experiments. Values in a column accompanied with different small letters are significantly different at $\mathrm{P}<0.05$ as indicated by DMRT.

and side of lamina. The $\mathrm{Mg}$ and $\mathrm{Ca}$ content of side of lamina (Figure 4) showed an increase by $738 \%$ in 0 week, $302 \%$ in 1 week, $245 \%$ in 2 weeks and $650 \%$ in 4 weeks compared with non-spraying group, respectively. All spraying group had more $\mathrm{Mg}$ and $\mathrm{Ca}$ content than nonspraying group. In particular, $\mathrm{Mg}$ and $\mathrm{Ca}$ content in 
Table 4. Fruit size according to the number of application of flower thinning chemicals $(\mathrm{cm})$.

\begin{tabular}{lccc}
\hline Treatment & Royaldaeseok & Formosa & Hongrosen \\
\hline Control group & $5.3 \pm 0.0^{\mathrm{b}}$ & $5.1 \pm 0.1^{\mathrm{b}}$ & $5.0 \pm 0.1^{\mathrm{b}}$ \\
Applied once & $6.1 \pm 0.0^{\mathrm{a}}$ & $6.1 \pm 0.2^{\mathrm{a}}$ & $5.3 \pm 0.1^{\mathrm{a}}$ \\
Applied twice & $5.5 \pm 0.1^{\mathrm{ab}}$ & $6.2 \pm 0.1^{\mathrm{a}}$ & $5.4 \pm 0.0^{\mathrm{a}}$ \\
\hline
\end{tabular}

Mean values \pm standard error represent the analyzed data pooled from three independent consecutively conducted experiments. Values in a column accompanied with different small letters are significantly different at $\mathrm{P}<0.05$ as indicated by DMRT.
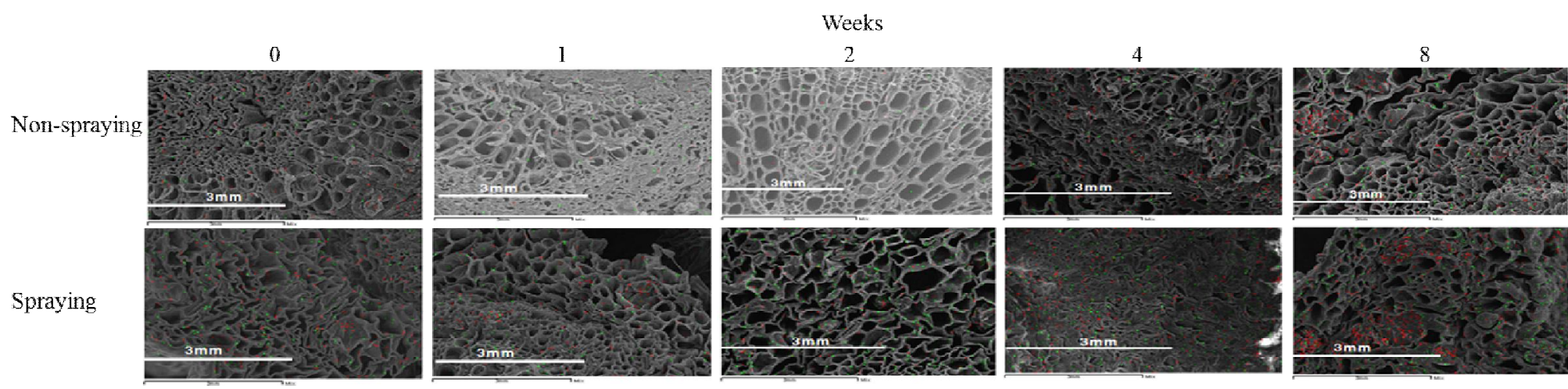

Figure 2. Analysis of petiole contents by spraying with flower thinning chemicals. Increase rate of Ca and Mg content compared to non-spraying; 0 week: $149 \%$, 1 week: $365 \%$, 2 weeks: $1,555 \%$, 4 weeks: $74 \%$, 8 weeks: $286 \%$.

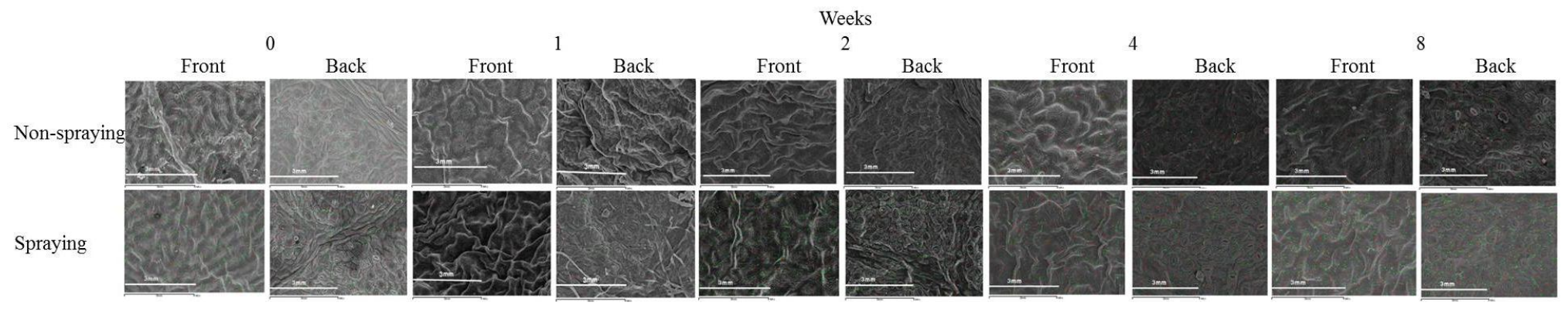

Figure 3. Analysis of content of lamina with spraying of flower thinning chemicals. Increase rate of $\mathrm{Ca}$, Mg content compared to non-spraying; 0 week: 87\%, 47\%, 1 week: $28 \%, 775 \%$, 2 weeks: $847 \%, 442 \%$, 4 weeks: $120 \%, 73 \%$, 8 weeks: $160 \%, 132 \%$. 

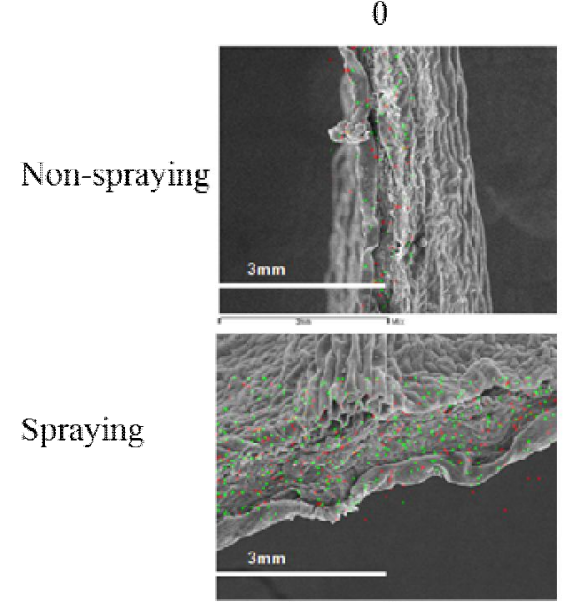

1
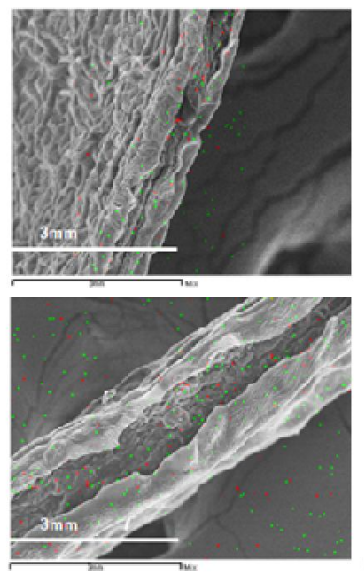

Weeks
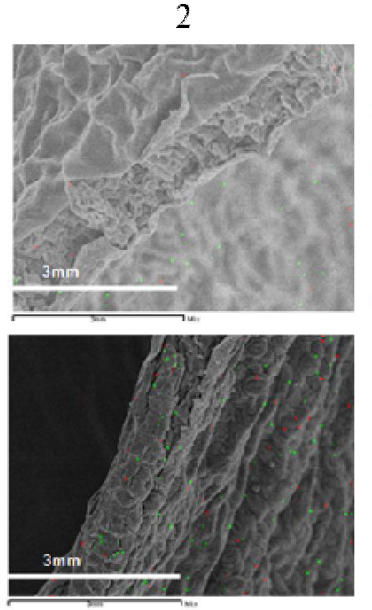

4
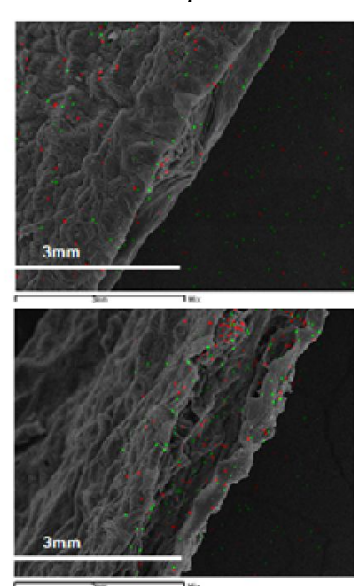
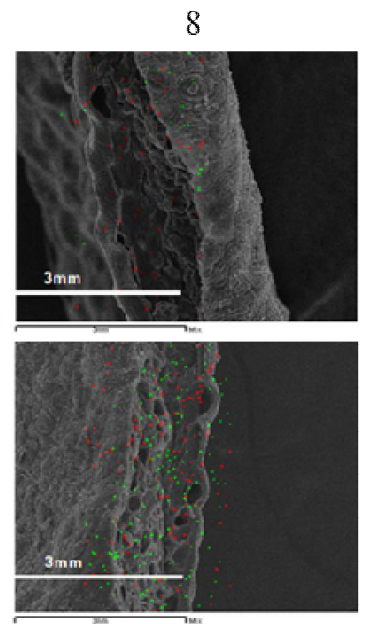

Figure 4. Analysis of side of lamina content with spraying of flower thinning chemicals. Increase rate of Ca, Mg content compared to non-spraying; 0 week: $738 \%$, 1 week: $302 \%$, 2 weeks: $245 \%$, 4 weeks: $650 \%$, 8 weeks: $1,246 \%$.

8 weeks after spraying increased by $1,246 \%$ compared with non-spraying group and showed highest content. As time passed, spraying group had more $\mathrm{Mg}$ and $\mathrm{Ca}$ than non-spraying group. The results suggest that the $\mathrm{Mg}$ and Ca content of nanoized flower thinning chemicals has moved from petiole to side of petiole.

\section{CONCLUSION}

In this study, we investigated the effect of flower thinning chemicals using wet nano-technology on the rate of flower thinning and yield of high-quality fruit. After spraying the redispersions with nanoized insoluble calcium and magnesium on the plums in each region by dilution rate the efficacy of flower thinning chemicals, quality characteristics of fruit by cultivars and calcium and magnesium content of leaves analysis was carried out. As a result of confirming the flower thinning rate, crop load and fruit set rate, the rate of flower thinning of 500 times and 250 times diluted solution was 5.7 times and 3.8 times higher than that of the control, respectively and the fruit set rate was 2.2 times, 3.4 times, and the crop load was measured twice and four times, respectively. In all flower thinning chemicals treatments, 500 times and 250 times diluted solution was more effective than the control. In addition, after 3 days of spraying with flower thinning chemicals, it was observed that there was no problem in flowering when spraying flower thinning chemicals. To confirm the fruit quality characteristics of the plums of different cultivars, we sprayed the flower thinning chemicals prepared through the nanoprocessing on the Royaldaeseok, Formosa and Hongosen cultivars and compared the crop load, fruit weight and fruit size. In the case of crop load according to the dilution rate, the effect was high in diluted flower thinning chemicals treatment group compared to the control group. Especially, it was confirmed that the effect of fruit set of all cultivars treated with 250 times dilution was about 19 to $48 \%$ higher than that of the control group. As a result of comparing the fruit weight with the number of application of flower thinning chemicals, all cultivars showed the effect of 14 to $60 \%$ on spraying once and 8 to $~ 52 \%$ on spraying twice compared to the control group. The reason for the decrease in the flower thinning effect at the time of spraying twice as compared with the spraying once is that the factors such as the weather conditions, the location of the orchard, the tree vigor, and the cultivation environment influenced the flower thinning effect and fruit quality (Guak et al., 2009; Yoo et al., 2014). Overall, the fruit weight and fruit size were higher in the plums of all cultivars sprayed with flower thinning chemicals than the control group. In order 
to confirm the compositional content and the migration route of the flower thinning chemicals that nano sized insoluble calcium and magnesium through the wet nano process, the leaves were divided into lamina, petioles and side of lamina at 0 week (control), 1 week, 2 weeks, 4 weeks, and 8 weeks after primary spraying on the plum leaves and analyzed by SEM, EDS. As a result of checking the petiole, calcium and magnesium contents increased by $1,555 \%$ at the 2 nd week after spraying, and showed the highest contents. Even at the 8 weeks, the content increased $266 \%$. In the case of side of lamina, the front and back sides increased by $2,847 \%$ and $442 \%$, respectively, at the 2nd weeks after spraying compared to non-spraying group. And the calcium and magnesium contents increased with the passing of time. In addition, calcium and magnesium contents of spraying group were increased compared to that of non-spraying group. Especially, it increased by $1,246 \%$ at the 8 weeks and showed the highest content. As time goes by, calcium and magnesium contents of all spraying group were higher than that of non-spraying group, suggesting that the insoluble calcium and magnesium components of the nanoized flower thinning chemicals migrated from petiole to lamina. In addition, the highest growth rate was observed in most of the experimental groups at 2 weeks after the first spraying and at 8 weeks after the second spraying, and the low growth rate was confirmed at 4 weeks. It is believed that the calcium and magnesium components of the flower thinning chemicals sprayed on the leaves of the plums flow or scatter by the external environment after 4 weeks of spraying. Therefore, it is necessary to maximize the flower thinning effect by respraying within 4 weeks in order to obtain the effect of flower thinning on plums. As a result of this study, it was concluded that the use of flower thinning chemicals by wet nano-process technology could inhibit the number of fruit set and produce high-quality fruit in fruit trees other than plums. In addition, it is expected to be applicable to various fields because it can be used in natural products and bio industries as well as plant nutrients.

\section{ACKNOWLEDGEMENT}

This study was carried out with the support of 'R\&D Program for Forest Science Technology (Project No. "2016018B10-1719-AB02") provided by Korea Forest Service (Korea Forestry Promotion Institute).

\section{REFERENCES}

Cho K, Yoon T, 2006. Fruit quality, yield, and profitability of 'Hongro' apple as affected by crop load. Kor J Hort Sci Technol, 24(2): 210215.

Chung KH, 1999. Morphological characteristics and principal component analysis of plums. Kor J Hort Sci Technol, 17: 23-8.
Garcia-Pallas I, Val J, Blanco A, 2001. The inhibition of flower bud differentiation in 'Crimson Gold' nectarine with GA3 as an alternative to hand thinning. Scientia Horticulturae, 90(3): 265-278.

Guak S, Kim EJ, Kook JR, Choi DG, 2009. MaxCel® as a postbloom thinner for 'Hongro' and 'Fuji' apples. Hort Environ Biotechnol, 50(3): 181-187.

Kim GH, Jeon YJ, Byun HG, Lee YS, Lee EH, Kim SK, 1998. Effect of calcium compounds from oyster shell bouind fish skin gelatin peptide in calcium deficient rats. Kor J Fisheries Aquat Sci, 31(2): 149-159.

Park SG, Kwon SJ, Kim YM, Lee SS, 2013. Reaction properties of noncement mortar using ground granulated blast furnace slag. J Kor Contents Assoc, 13(9): 392-399.

Yoo J, Kang B, Kim D, Lee J, Lee D, Kweon H, Myung Cl, Young JH, Gun CM, Geun CD, Kang I, 2016. Effect of flower and fruit thinner on fruit set and fruit quality of 'Gamhong' apples. 34(1): 24-31.

Yoo J, Park MY, Kang IK, 2014. Effect of fruit thinner on fruit set and quality in 'Hongro' and 'Fuji' apples. Kor J Hort Sci Technol, 32: 577 583.

Yun SK, Bae H, Yoon IK, Chung KH, 2013. Effect of GA paste on physiological fruit drop and fruit characteristics in 'formosa' plums (Prunus salicina Lindl.). Korean J Hortic Sci, 22:309-315

Zhang M, Zhang CJ, Shrestha S, 2005. Study on the preparation technology of superfine ground powder of Agrocybe chaxingu Huang. J Food Eng. 67(3): 333-337.
Citation: Lee SH, Lee SM, So S, Choi YS, Jang YH, Kim KM, Chung IK, 2018. Effect on flower thinning by using nano-processing technology chemicals in plum (Prunus salicina Linnaeus). Net J Agric Sci, 6(3): 4248. 